\title{
Ecofriendly Decolorisation of Textile Waste Water Using Natural Coagulants
}

\author{
P. Sasirekha ${ }^{1}$, S. Shankar Krishna ${ }^{2}$, S. Vembukumar ${ }^{3}$ and L. Vignesh \\ ${ }^{1}$ Assistant Professor, ${ }^{2,3 \& 4}$ Student \\ ${ }^{1,2,3 \& 4}$ Department of Civil Engineering, Sethu Institute of Technology, Tamil Nadu, India \\ E-Mail: sasir512@gmail.com, shankarholmes23@gmail.com, vembukumar02@gmail.com, lpdevicki@gmail.com
}

\begin{abstract}
The Process of production of textile or wet treatment and finishing processes of textile materials are huge consumers of water with high quality. As a result of these various processes, considerable amounts of polluted water are released. The project emphasis on the problem of environmental protection against waste water generated by the industry. The selection of the purification method depends on the composition and types of waste water. Plant extracts are used as natural coagulants for decolorizing the dye effluents. Removal of toxic substance from the discharged effluent is paramount. Chemical treatment techniques are effective for color removal but require more energy and expensive than biological process. They contaminate the environment and require additional cost for disposal.
\end{abstract}

Keywords: Natural Coagulants, Decolorisation, Wastewater, Ecofriendly

\section{INTRODUCTION}

Water is the main component used in all types of industries. Water used for different processes is not completely utilized and is discharged as wastewater. Textile industry is one of the biggest consumer of potable water as well as chemicals used during textile processing stages. With the increased demand for textile products, there is increase in the textile industry and its wastewater proportionally, making it one of the main sources of severe pollution problems worldwide. In particular, the release of colored effluents into the environment is undesirable, not only because of their color but also because of the breakdown products. The release of colored wastewater in the ecosystem is a remarkable source of aesthetic pollution, eutrophication, and perturbations in aquatic life.

Dyeing \& finishing stages are the major producer of wastewater with complex characteristics. The unused dyes $\&$ chemicals are discharged as dye effluents from various units. The main pollutants of textile wastewater originates from the dyeing and finishing steps that involve dying of the man-made or natural fibers to the desired permanent color and processing of those fibers into final commercial products. Dyes are synthetic and aromatic molecular structural compounds. These are basically chemical compounds that can attach themselves to fabrics or surfaces to impart color. Over 100,000 commercially available dyes exist and more than $7 \times 10^{5}$ metric tons of dyestuff are produced worldwide annually. During the dyeing processes about $10-90 \%$ of the dyestuff do not bind to the fibers and therefore, released into the sewage treatment system or the environment. Colored industrial effluents from the dyeing industries represent major environmental problems (Knapp, J. S., and Newby, P.S. 1995) [3].

Dyeing industry effluents are one of the most problematic wastewaters to be treated not only for their high chemical oxygen demand, but also for high biological oxygen demand, suspended solids, turbidity, toxic constituents but also for color, which is the first contaminant discernible by the human eye. (O'Neill, C., Hawakes, F. R., Hawakes, D.L., and Wilcox, S. J. 1999) [6]. Therefore, industrial effluents containing dyes must be treated before their discharge into the environment. Dyes can absorb light with wavelength in visible region $(350-700 \mathrm{~nm})$; they are colored and are detectable even in the concentration of $1 \mathrm{mg} / \mathrm{L}$. Furthermore, the absorption of light due to textile dyes creates problem to photosynthetic aquatic plants and algae. There are extreme fluctuations in different parameters such as chemical oxygen demand (COD), BOD, $\mathrm{pH}$, color, and salinity with textile processing.

The wastewater composition will depend on the different organic-based compounds, chemicals, and dyes used in the industrial dry and wet-processing steps. The application of a coagulation/flocculation process is applied in wastewater treatment to remove turbidity, color and natural organic matter. Chemical treatment techniques are effective for color removal but require more energy and expensive than biological process. They contaminate the environment and require additional cost for disposal. Moreover, some studies have reported that residual aluminum sulphate and poly aluminium chloride may include Alzheimer's disease, whereas the synthetic organic polymers, such as acryl amide have neurotoxic and carcinogenic effects.

\section{INEVITABILITY OF COAGULATION}

Groundwater and surface water contain both dissolved and suspended particles. Coagulation and flocculation are used to separate the suspended solids portion from the water. Suspended particles vary in source, charge, particle size, shape, and density. Correct application of coagulation and flocculation depends upon these factors. Suspended solids in 
water have a negative charge and since they have the same type of surface charge, they repel each other when they come close together. Therefore, suspended solids will remain in suspension and will not clump together and settle out of the water, unless proper coagulation and flocculation is used. Coagulation and flocculation occurs in successive steps, allowing particle collision and growth of floc. This is then followed by sedimentation. If coagulation is incomplete, flocculation step will be unsuccessful, and if flocculation is incomplete, sedimentation will be unsuccessful.

Coagulant chemicals with charges opposite those of the suspended solids are added to the water to neutralize the negative charges on non-settable solids (such as clay and color-producing organic substances). Once the charge is neutralized, the small suspended particles are capable of sticking together. These slightly larger particles are called microflocs, are not visible to the naked eye. Water surrounding the newly formed microflocs should be clear. If not, coagulation and some of the particles charge have not been neutralized and hence more coagulant chemicals may need to be added. A high- energy, rapid-mix to properly disperse coagulant and promote particle collisions is needed to achieve good coagulation. Over-mixing does not affect coagulation, but insufficient mixing will leave this step incomplete. Contact time in the rapid-mix chamber is typically 1 to 3 minutes.

Coagulation and flocculation are essential processes in various disciplines. In potable water treatment, clarification of water using coagulating agents has been practiced from ancient times. As early as 2000 BC the Egyptians used almonds smeared around vessels to clarify river water. The use of alum as a coagulant by the Romans was mentioned in around 77 AD. By 1757, alum was being used for coagulation in municipal water treatment in England.

In modern water treatment, coagulation and flocculation are still essential components of the overall suite of treatment processes - understandably, because since 1989 the regulatory limit in the US for treated water turbidity has progressively reduced from 1.0 NTU in 1989 to $0.3 \mathrm{NTU}$ today. Many water utilities are committed to consistently producing treated water turbidities of less than 0.1 NTU to guard against pathogen contamination. Coagulation is also important in several wastewater treatment operations. A common example is chemical phosphorus removal and another, in overloaded wastewater treatment plants, is the practice of chemically enhancing primary treatment to reduce suspended solids and organic loads from primary clarifiers.

\section{MATERIALS AND METHODS}

\section{A. Effluent Samples}

Textile effluent samples were collected from the hinterlands of industry located at Thiruppur. The effluent samples were collected aseptically in plastic container and stored in a nonreactive environment.

\section{B. Preparation of Natural Coagulants Powder}

The leaves of guava, pineapple, calotropis, and the whole seed of mango and the dried slices of sugar beet were ground to fine powder using laboratory mill and sieved.

\section{Extraction of Coagulants}

The active component from coagulants was extracted using distilled water $\left(\mathrm{dH}_{2} \mathrm{O}\right)$. Ten grams of powdered coagulants was suspended in $1 \mathrm{~L}$ of $\mathrm{dH}_{2} \mathrm{O}$ solution. The suspension was stirred manually by hand for ten minutes to extract active coagulation component. The solution was filtered using a clean white cloth. The resultant filtrate solution was used as a coagulant. In order to prevent any aging effects such as change in $\mathrm{pH}$ and coagulation activity due to microbial decomposition of organic compounds during storage a fresh solution was prepared for each sequence of experiments.

\section{Coagulation Experiments}

Coagulation studies were conducted in triplicate using jar test. The dye effluent $(150 \mathrm{ml})$ was filled into the beakers $(200 \mathrm{ml})$. Add varying dose of coagulants i.e. from $10 \mathrm{mgL}^{-1}$ to $40 \mathrm{mgL}^{-1}$ to each beaker and mixed for 1 minute at 100 rpm for rapid mixing followed by 20 minutes slow mixing at $30 \mathrm{rpm}$. All suspensions were then left to sedimentation; after 20 minutes of sedimentation, upper clarified liquid was collected from the top of the beaker.

\section{E. Analytical Method}

All analytical methods followed the standard methods. Turbidity was measured using a turbidity meter (SUNTRONICS ST-232) and it was expressed in nephelometric turbidity units (NTU). The pH measurements were made on a digital pH meter (SUNTRONICS S202). The coagulation experiments were conducted using Jar test.

\section{RESULTS AND DISCUSSION}

\section{A. Determination of Hydrogen Ion Concentration (PH)}

The upper clarified water from jar test is taken in a beaker and the electrode of $\mathrm{pH}$ meter is immersed and the readings are observed. The $\mathrm{pH}$ measurements were made on a digital $\mathrm{pH}$ meter (SUNTRONICS S202). PH is a term generally used to express the intensity of the acid or alkaline condition of a solution. It is a way of expressing the hydrogen ion concentration. It is defined as the logarithm of reciprocal of the hydrogen ion concentration in moles per liter. The $\mathrm{pH}$ scale values ranges from 0 to 14; the value of 0 to less than 7 ranges indicates acidity and greater than 7 to 14 , alkalinity. The $\mathrm{pH}$ value of 7 represents the neutral solution and it has little significance. 


\section{B. Determination of Turbidity}

The upper clarified water is taken in a cuvette of $40 \mathrm{ml}$ capacity and kept in digital nephelo meter. Turbidity was measured using a turbidity meter (SUNTRONICS ST-232) and it was expressed in nephelometric turbidity units (NTU). Turbidity is caused in natural water by finely divided suspended particles of clay, Loam and sand or by microorganisms. It is expressed in parts per million by weight as determined by optical observations.

\section{Determination of Chloride}

Chloride in the form of chloride ion is one of the major anions in water and sewage. The amount of chloride should not exceed $250 \mathrm{mg} / \mathrm{L}$ in domestic water supply. It is exceeds that, then it gives salty taste to water. The amount of chloride present in excess in any water is an important factor in determining the type of desalting method to be used.

\section{Determination of Bio-Chemical Oxygen Demand (BOD)}

Bio-Chemical oxygen demand (B.O.D) is defined as the amount of oxygen required by bacteria and other microorganisms during the biochemical degradation and transformation of organic matter in waste water under aerobic condition. It is used

1. To determine the approximate quantity of $\mathrm{O}_{2}$ that will be required to biologically stabilize the organic matter present.

2. To determine the strength of sewage and industrial effluents.

3. To measure the purification capacity of streams and so to design a treatment facilities accordingly.

4. To determine the size of trickling filter and activated sludge unit.

5. To ascertain the efficiency of various treatment units.

\section{E. Determination of Chemical Oxygen Demand (COD)}

The chemical oxygen demand (COD) is an indicative measure of the amount of oxygen that can be consumed by reactions in a measured solution. It is commonly expressed in mass of oxygen consumed over volume of solution which in SI units is milligrams per liter $(\mathrm{mg} / \mathrm{L})$. A COD test can be used to easily quantify the amount of organics in water. It indicates the amount of oxygen required to oxidize the carbonaceous matter. The main advantage is that its determination takes 3 hours compared to the 5 days B.O.D. It is used to measure the pollution strength of domestic and industrial waste.

From the results the following interpretations were arrived

1. Pineapple leaf powder is efficient in $\mathrm{pH}$ and turbidity reduction of the effluents.

2. Mango seed powder and sugar beet pulp is proficient in chloride, BOD and COD reductions of the effluents.
3. The other two coagulants are for mild treatment of the effluents.

4. The overall cost for the treatment is highly economic.

5. The color removal is higher if the settling time is longer.

6. The metamorphosis produces $80 \%$ of the dye effluents as treated water.

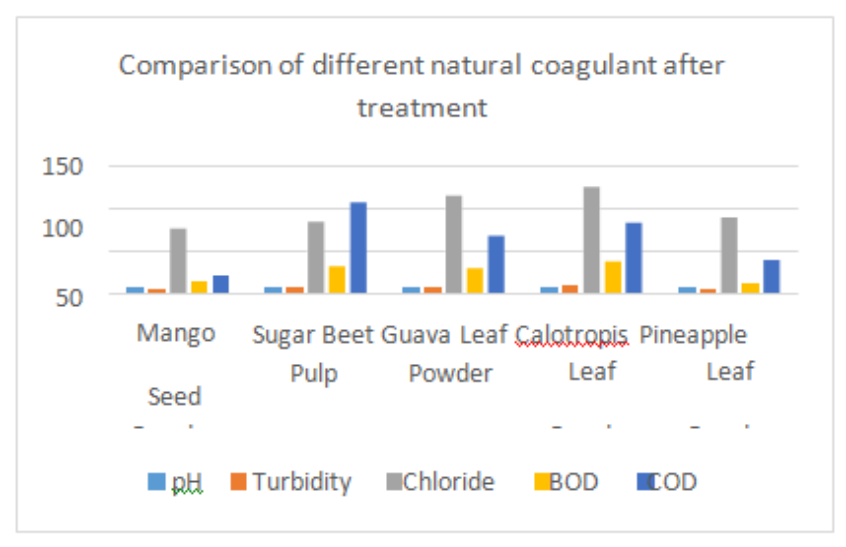

Fig. 1 Parametric Results

\section{CONCLUSION}

It is important to develop a biodegradable and eco-friendly organic coagulant without secondary pollution for wastewater treatment. $\mathrm{PH}$ and Coagulant dose are important factors influencing the mechanism of coagulation. The type and chemical structure of the dyes plays an important role in the coagulation process. Conventional Technologies to treat textile waste water include combination of biological, physical and chemical methods but requires high capital and operating costs. Biological treatments can efficiently remove dyes from large volumes of waste water at low costs. Need of the day is to substitute hazardous chemicals by using environment friendly methods. Best approach to reduce waste water discharge is to manufacture ecofriendly products and to modify certain areas of textile processing into avoid toxicity. From the observation it is clear that the coagulant of mango seed powder has proven to be most effective in treatment of dye effluents. Coagulants of pineapple leaf powder and guava leaf powder can be used for medium treatment. Coagulants of calotropis leaf powder and sugar beet pulp can be used for $\mathrm{pH}$ and turbidity reduction. Maximum decolorization was observed by Mango seed powder in textile dye effluent.

\section{REFERENCES}

[1] Akshaya Kumar Verma, Rajesh Roshan Dash, and Puspendu Bhuniain, "A review on chemical coagulation/flocculation technologies for removal of colour from textile wastewaters", Journal of Environmental Management, Vol. 93, No.1, pp. 154-168, Jan. 2012.

[2] F. Bouatay, and F. Mhenni, "Use of the cactus cladodes mucilage (Opuntia ficus indica) as an eco-friendly flocculants: process development and optimization using statistical analysis", International Journal of Environmental Research, Vol. 8, No. 4, pp.1295-1308, autumn 2014. 
[3] J. S. Knapp, and P.S. Newby, "The microbiological decolorization of an industrial effluent containing a diazo-linked chromophore", Water Research, Vol. 29, No. 7, pp. 1807-1809, July 1995.

[4] Muhammad Shahzad Zafar, Muhammad Tausif, Muhammad Mohsin, Syed Waqas Ahmad, and Muhammad Zia-ul-Haq, "Potato Starch as a Coagulant for Dye Removal from Textile Wastewater", Water, Air, \& Soil Pollution, Vol. 226, No. 8, pp. 1, 2015.

[5] Naz Chaibakhsh, Neda Ahmadi, and Mohammad Ali Zanjanchi, "Use of Plantago major L. as a natural coagulant for optimized decolorization of dye-containing wastewater", Industrial Crops and Products, Vol. 61, pp. 169-175, Nov. 2014.

[6] C. O'Neill, F. R. Hawakes, D. L. Hawakes, and S. J. Wilcox, "Anaerobic-aerobic biotreatment of simulated textile effluent containing varied ratios of starch and azo dye", Water Research, Vol. 34, No. 8, pp. 2355-2361, June 2000.
[7] Rashmi Sanghi, Bani Bhattacharya, Awantika Dixit, and Vandana Singh, "Ipomoea dasysperma seed gum: An effective natural coagulant for the decolorization of textile dye solutions", Journal of Environmental Management, Vol. 81, No. 1, pp. 36-41, October 2006.

[8] Rashmi Sanghi, Bani Bhattacharya, and Vandana Singh, "Use of Cassia javahikai seed gum and gum-g-polyacrylamide as coagulant aid for the decolorization of textile dye solutions", Bioresource Technology, Vol. 97, No. 10, pp. 1259-1264, July 2006.

[9] Sorour Shamsnejati, Naz Chaibakhsh, Ali Reza Pendashteh, and Sam Hayeripour, "Mucilaginous seed of Ocimum basilicum as a natural coagulant for textile wastewater treatment", Industrial Crops and Products, Vol. 69, pp. 40-47, July 2015. 